\title{
Working with the metaphor of life and death
}

Phil Barker University of Newcastle upon Tyne, Newcastle upon Tyne

\begin{abstract}
The experience of being human is intangible. As a result, descriptions of human experience rely heavily on metaphor to convey something of that whole lived experience. By contrast, contemporary scientific narratives of the mind emphasise the form of human thought and emotion, over the content of people's experience, where constructive attempts are made to explain the experience of self, through metaphorical allusion. This paper considers the importance of metaphor as a vehicle for expressing and exploring selfhood. Examples from the psychiatric literature, as well as from the visual and literary arts, are used to reflect on the importance of metaphor in clarifying the meanings of the constructs of health and illness.

(f Med Ethics: Medical Humanities 2000;26:97-102)
\end{abstract}

Keywords: Metaphor; phenomenology; ontology; mental health

I know only three things. ${ }^{1}$ First, life is a story best understood as an evolving narrative. Moment by moment, the vagaries of experience are recorded on our own tabula rasa, until the book is finally closed. Second, the story of my life is illuminated, pictorially, inside my head. I hear and talk in words, but the story emerges as a lived experience: I see and feel a sense of place. And finally, it is impossible to relate any aspect of my life experience directly. I need to use a foreign word or phrase to evoke its near-inexpressibility. Life is so real I can meaningfully represent it only in metaphor.

These observations appear unexceptional. However, even where metaphor is an essential part of everyday communication, awareness of its location within discourse, is not always present. Thomas Szasz once told how a medical student claimed to know what a metaphor was, but could not offer an example, saying "my mind is a blank". Szasz laughed, but his class of educated young people did not, and he realised that they did not really "know" metaphor. ${ }^{2}$ In a related vein, C S Lewis noted that:

"We must use metaphors. The feelings and the imagination need that support. The great thing ... is to keep the intellect free from them: to remember that they are metaphors. ${ }^{3}$

This emphasises the great paradox of communication: that we use a linguistic artifice to communicate the essence of our experience, all the time running the risk that we shall lose this essence in the translation; and might also lose our audience in the process. The Scots, to whom metaphor is not wholly unknown, have been known to express their scorn for the too-clever use of metaphor with the use of another metaphor: "you're so sharp you'll cut yourself".

The problems of living that we blithely call illness or health are so complex that we try to objectify them-through metaphors-perhaps as a means of containing our anxiety. The disturbance of brain chemistry, for example, that many believe lies at the root of some forms of mental illness-such as depression and schizophrenia-does not involve a disturbance as we might know it in the world-a fracas. Nor does this "lie" anywhere, least of all at the base (or root) of anything. Un-picking the simple metaphors used to explain our understanding of brain chemistry also pulls the rug from under them-to employ another metaphor. The metaphorical map is not the territory. Even scientific maps are metaphorical.

This use of metaphor serves as a linguistic anchor for our confused attempts to understand a potentially ineffable phenomenon. In ordinary discourse, people talk of being "at the end of their tether", "unable to see the light at the end of the tunnel", "at the end of the road", "all washed up", or a "shadow of their former selves". It is difficult to make any meaningful statement about oneself or life in general without recourse to metaphor. ${ }^{4}$ As one of the modern masters of the critical appraisal of metaphor, at least in psychiatry and psychotherapy, has noted:

"A man dies and his young son is told that he went to heaven. However, when a man dies and goes to heaven, his going is not the same sort of action as that entailed in his widow going to Italy, nor is heaven the same sort of place as Rome. A man comes home and as he walks through the front door calls to his wife, 'Honey, I am home'. (He is of course neither of these things). Like jokes, which they so closely resemble, metaphors like these cannot be explained, If one tries to do so, in the process, to use another metaphor, one succeeds only in killing them.

Even where manifest physical pathology is present-as in carcinoma-the patient's metaphorical description of pain, fatigue, or the perceived ebbing of the life force, does not represent a mirror image of cancerous cells. It is 
likely that such metaphors are rather than reflect the whole, lived experience of illness. ${ }^{6}$

The arts possess great potential to help us understand the difficulties of life in general, but also of complex concepts like health and illness. Great art expresses the inexpressible, yet does so indirectly. "This is not a pipe" wrote Magritte beneath his famous painting of a large pipe. In his typically mischievous way, Magritte was telling the truth and deceiving us, at one and the same time. Things just "are". When we re-present them, they become something else, and appearances are deceptive.

The careful and, in some cases, clever use of language can help us to get close to experiences, by approaching them indirectly. We can lose ourselves in an experience, when metaphor-whether verbal or visual-helps us "see" something for what it really is, by using a phrase or image which clearly belongs to something else, as Aristotle first said. This strange kind of "losing" of our selves, was addressed by Robert Pirsig when he observed that if we can lose the subject-object duality that dominates much of our lives, we become at one with what we are doing. ${ }^{7}$ This becomes a kind of "atonement". Through this "at-one-ness" we reconcile our differences, even with physical aspects of our world, and can be said to "care" about what we are doing. We can also be said to be engaging with reality directly. Alan Watts noted that in the West we are uncomfortable with anything other than a dualistic view of our everyday universe.

On being asked how to escape from the "heat" another master directed the questioner to the place where it is neither hot nor cold. When asked to explain himself he replied, "In summer we sweat; in winter we shiver". Or, as a poem puts it:

"When cold, we gather round the hearth before the blazing fire;

When hot, we sit on a bank of the mountain stream in the bamboo grove".

And from this point of view one can:

"See the sun in the midst of the rain;

Scoop clear water from the heart of the fire". ${ }^{8}$

For Watts, this was not about submission to the inevitability of sweating when it is hot and shivering when cold, eating when hungry, and sleeping when tired:

"Submission to fate implies someone who submits, someone who is the helpless puppet of circumstances, and for Zen there is no such person. The duality of subject and object, of the knower and the known, is seen to be just as relative, as mutual, as inseparable, as every other. We do not sweat because it is hot; the sweating is the heat. It is just as true to say that the sun is light because of the eyes as to say that the eyes see light because of the sun. The viewpoint is unfamiliar (at least until the development of quantum physics) because it is our settled conven- tion to think that heat comes first and the, by causality, the body sweats. . . . Thus the Zenrin Kushu says:

Fire does not wait for the sun to be hot,

Nor the wind for the moon, to be cool'."

This ancient wisdom suggests the relationship between "things" and the concepts that we use to represent them. Thich Nhat Hanh discussed the need to bring light to the gap between things themselves and the concepts we have of them:

"Things are dynamic and alive, while our concepts are static. Look, for example at a table. We have the impression that the table itself and our concept of it are identical. In reality, what we believe to be a table is only our concept. The table itself is quite different. Some notions - wood, brown, hard, three feet high, old etc-give rise to a concept of table in us. The table itself is always more than that. For example, a nuclear physicist will tell us that the table is a multitude of atoms whose electrons are moving like a swarm of bees, and that if we could put these atoms next to each other, the mass of matter would be smaller than one finger. This table, in reality, is always in transformation; in time as well as in space it is made only of non-table elements. It depends on these elements so much that if we were to remove them from the table, there would be nothing left."

There is, perhaps, a strange irony that this balance of contemporary physics and Oriental psychology is to be found in a book by a meditation master, whereas the authors of many texts on contemporary psychology, not to mention the utterings of our political masters, talk as if our concepts-of personality disorder and schizophrenia-and the people to whom they are applied-patients-are one and the same "thing".

I recall vividly, the first time I experienced the "no-self" that Watts and Thich Nhat Hanh talk about. Almost 30 years ago, I prepared a corpse, for the first time, to be taken to the mortuary. I lost all sense of myself, and was sucked into the enormity of this engagement with a body that was alive an hour ago but now was deemed lifeless. In effect, I gave up the emotional and intellectual struggle to "understand" what it meant for this man no longer to exist, conceptually, and as a result I experienced the "cathedral of care". Metaphorically the "I" that was "me" became lost in the necessarily careful and respectful action of dressing after death. When $\mathrm{Mu}-\mathrm{Chou}$ was asked:

"We eat and dress every day, "how do we escape from having to put on clothes and eat food?' he answered, 'we eat and dress; we eat.' 'I don't understand', said the monk. 'If you don't understand, put on your clothes and eat your food."”8

My friend, the social worker, academic, psychotherapist, and Zen Buddhist monk recounted a similar story, bred of the same frustrated searching. He noted that: 
"Shamanic practice turns its back on Homer's Calypso and the struggle to be superman or woman. Instead it takes a paradoxical journey, in arriving back at the same place. My abbot answered my question on the day of ordination: 'what does it mean to be a monk?' 'Tomorrow morning, a Zen monk will wake up in your bed and go get some breakfast.' I could have killed him but it took me years to appreciate his response."10

The Irish poet and mystic, W B Yeats, appeared to have wrestled with similar questions and, ultimately came to know a similar wisdom:

"Labour is blossoming or dancing where

The body is not bruised to pleasure soul,

Nor beauty born out of its own despair,

Nor blear-eyed wisdom out of midnight oil.

$\mathrm{O}$ chestnut tree, great rooted blossomer,

Are you the leaf, the blossom or the bole?

$\mathrm{O}$ body swayed to music, $\mathrm{O}$ brightening glance

How can we know the dancer from the dance?"11

Intuitively, perhaps, as I dressed that man for his last corporeal journey, I discovered the world of experience that Thich Nhat Hanh discussed-a world in which "things" are dynamic and alive, and even the dead are dynamically alive to us, should we let them.

By talking with people about death-and especially death by suicide-I have learned that not everyone submits so readily to the simulated lessons offered by Dr Death. Although Plato despaired of poetry, experience of people in various states of ill health, especially near death, leads me to conclude that the poet, the novelist and the artist, can grasp the nuances of the inexpressible, making it not only real, but meaningful. However, the closest artists have often got to medicine has been as mere illustrators of the hardware of life. We all can feel the pain and distress of patients - our problem often is to contain that emotional knowledge. Where do we put it? The metaphorical wisdom of art and literature allows us to grow a compassion for our fellow women and men, by experiencing something of the inexpressibility of their experience, without risking our emotional selves in the process.

Health care today is being rapidly overtaken by a different kind of metaphorical language that might be called ugly and obfuscatory. Were he still with us, Orwell might include Health-Speak in the same class as Newspeak. This is especially true of mental health where, in addition to the gratuitous creation of disorders within, for example, the Diagnostic and Statistical Manual (DSM IV), we introduce into clinical parlance politically loaded terms such as "seriously mentally ill", implying that there might be some people whose mental illness is a trivial affair. The language of clinical medicine, like that of politics, has always aimed to put distance between us-who assume ourselves to be sane and "normal" - and the "objects" of our clinical attention, concern and oftentimes, pity. One does not need to be a Zen master, or a quantum physicist, to realise that such a distinction is illusory. It is a function of self deceit.

I have long considered the core business of psychiatry to be one form of organised response to people in great human distress. In an attempt to refocus on the human issues in mental health, I asked a group of people from around the world, who had experience of psychosis, to describe their descent into, and journey beyond, madness. ${ }^{12}$ Here, I employ madness as a metaphor for the extremes of human distress, found in all forms of illness, using this as a means of considering how metaphor might help us develop our understanding of illness-how we might get close, while still remaining at a distance.

In From the Ashes of Experience Cathy Conroy reflected on her many years of struggle with mania and deep alienating depression, and concluded her tale with a call for an ecological vision of individual human and social development. She wrote:

"I want to see such a vision reflected in the statutory mental health services-individual reflection about who and what people are in their lives."13

However, professionals often find it difficult to face their own reflections, which they find in the faces of their patients. Cathy added that:

"When there is an opportunity for modelling new possibilities, for different illuminated paths, paths with heart, true exploration of our predicament can take place." ${ }^{\prime 13}$

The pathway Cathy alludes to here is very different from our contemporary notion of "clinical pathways" but shares the same metaphor. Clinical pathways have little interest in who or what people are in their lives, but merely develop a string of concepts that aim to manage another concept - the illnesses that are assumed to afflict people. Cathy recognises the danger that we might (metaphorically) lose sight of the path that has become so important to her, and calls on us to use our intuitive powers to grasp something of the awful darkness of madness, believing that intuition might afford us insights that:

"spring from anguish, wounding, stigma, alienation in single rooms, labels, suffering, altered consciousness, desolation, and betrayals." 13

Even a tiny insight into such anguish and betrayal might, in my view, be worth mountains of what we now-ubiquitously-call "evidence". However, such intuitive evidence-especially when generated by people described as the "seriously mentally ill" - is often deemed to be inferior, when it is considered at all.

Another writer in the same book, Simon Champ, struggled with what is described as paranoid schizophrenia for 23 years. That he is a warm, engaging, witty and self-effacing man, is testimony not only to the success of the struggles of his human 
heart, but also evidence of how little we understand the phenomena we label "paranoid schizophrenia". We can tell Simon nothing about his experience, but there is much that he can teach us. Simon noted that having begun to come to terms with the sense of bereavement felt over the many years lost to his illness, he began to see clearly the difficult path he had followed, and gained a glimpse of the new horizons ahead.

"In some ways it feels as if I've come home to myself, a self changed, a self I last felt at 17 , and yet now I'm near 40. All those years of experiences separate me from the teenager I was, but somewhere inside I'm complete again, as I used to be then. In between, despite having schizophrenia, I've lived a full life. So what was missing? What has returned? What is that quality of being, so hard to define, that is an essential part of what I'm trying to understand, a kind of being-in-the-world, - in reality?" "12

Simon Champ invites us to consider mental illness from a distinctly phenomenological perspectiveasking us to empathise with the ontological problems of being in such an illness state. Such an interest in the phenomenon of the person in mental illness appears to weaken daily.

Many now argue that the education of all non-medical mental health professionals, but especially nurses, should incorporate more of an emphasis on neuro-anatomy and pharmacology, asserting that this will equip nurses to better explain mental illness and its treatment. ${ }^{14}$ What is rarely addressed, is the assumption that this biological and pharmacological discourse is the only one requiring development. What of our need to understand better the vexed question of personhood and the largely socially and culturally constructed meanings of health and illness? We might also ask, what of the fear of madness, not to mention the fear of deterioration and decay that appears to lie within us all?

Some of us will have an opportunity to learn something of this through direct learning from patients - even when they are deceased. There is no substitute for such a direct education. However, we have learned about the world in a vicarious way ever since we began to tell stories round our neolithic campfires. The enduring appeal of Shakespeare is that his stories appear to hold eternal truths about the human condition. The psychiatric canon today is represented by the classification systems of the International Classification of Diseases (ICD-10) or the DSMIV. Although he had no interest in classification, the Bard's dramatic works captured many forms of psychiatric disorder. By reading these works we get a chance to get a sense of the character-as a lived experience, not as an object. Talking about his experience of playing Hamlet the RSC actor, Mark Rylance, observed:

"Perhaps that's why there are so many books written about Hamlet; yet none of them could explain what some of the lines meant. It took me 80 or 90 performances before I learned what some of them meant. There is no way you can do it with a dictionary or rational thought. It is only through play that you get there." ${ }^{15}$

Rylance made a critical point, not simply for those who experience what might be called mental illness, but for society as a whole. To know illness we need to get inside of the experience, we need to empathise. All health and social care professionals (not to mention other members of society) could get close to the point of Rylance's experience by immersing ourselves - as he did-in the "role" of the patient, whatever the condition. However, this is close to psychodrama and may be too threatening for many people in health care.

Most of us learn to cope with the life and death scenario with denial, and it would be folly to ban the use of this aged means of facing the distress in others. However, we might care to remember the value of reading, watching or discussing the dramatic re-enactment of a life as a fine substitute for direct experience. English literature has a hoard of books that help us to appreciate the human significance of various forms of illness. In my field of psychiatry William Styron's Darkness Visible, explores depression; Daphne Du Maurier's Rebecca, anxiety; Janet Frame's Faces in the Water, psychosis; C S Lewis's A Grief Observed, bereavement; Doris Lessing's Briefing For a Descent Into Hell, withdrawal; Susanna Kaysen's Girl Interrupted, teenage breakdown; Kafka's Metamorphosis, identity crisis, and Malcolm Lowry's Under the Volcano, alcoholism. There are many more.

The great value of these books is that they are more real than reality, by virtue - paradoxically - of their distance from reality. To get this close one needs to keep one's distance, which might be a form of dramatic irony in itself. These artistic accounts occupy a different body of human understanding, from that of the biological, psychological or social sciences, which employ a different kind of distance from the subject: not in any way better, just different.

In consideration of this paradox of striving and reaching knowledge, Rilke wrote:

"Being an artist means: not numbering and counting, but ripening like a tree, which doesn't force its sap, and stands confidently in the storms of spring, not afraid that afterward summer may not come. It does come. But it comes only to those who are patient, who are there as if eternity lay before them, so unconcernedly silent and vast. I learn it every day of my life, learn it with pain I am grateful for: patience is everything." 16

People who wish to learn the art of caring need to begin with the exercise of patience. Through patience the sap of our caring capacity rises, our capacity for healing ripens slowly within us, as Rilke suggested.

It is notable that great scientists also have recognised the virtue of such patient inquiry, which yields a compassion and connection with others, if not to the whole of life. 


\section{Einstein wrote:}

"A human being is part of the whole that we call the universe, a part limited in time and space. He experiences himself, his thoughts and feelings, as something separated from the rest-a kind of optical illusion of his consciousness. This illusion is a prison for us, restricting us to our personal desires and to affection for only the few people nearest us. Our task must be to free ourselves from this prison by widening our circle of compassion to embrace all living beings and all of nature."17

Einstein may have been hinting that we already possess all that we need to become healers. This lies within us - we do not need to go anywhere to get it. In a similar vein, Wittgenstein wrote:

"If the place that I want to arrive at could only be reached by a ladder, I would give up trying to arrive at it. For the place I really have to reach is where I must already be. What is reachable by a ladder doesn't interest me." 18

Wittgenstein was adding literal force to the metaphorical view of the attainment of true wisdom expressed by Albrecht Dürer in his famous engraving Melancholia. The most common interpretation of Dürer's Melancholia is that of the defeated intellect, which seeks solace in a higher plane of existence, in the next world. On the contrary, I think that Dürer-a practised melancholic himself - saw the value of melancholia as a part of the creative process. Dürer had become fascinated with mathematics - ratio in particular-as a means of developing the perfect form of expressing reality. The central image of the winged angel of the Intellect (which probably is a self portrait) sits staring disconsolately at a scattering of mathematical devices on the ground. These instruments have failed him, or perhaps he has simply failed to exploit their potential. We are, perhaps, back with Watts and Thich Nhat Hanh. Dürer appeared to be saying that melancholy obliges us to seek alternative solutions to life's problems. It leads to an enhanced level of understanding on the material plane of existence- - here and now-not on any celestial plane. The ladder, which will serve as the metaphorical steps towards enlightenment, leansalmost casually - against the wall behind the great winged figure. The enlightenment, which this representation of our intellectual selves seeks, lies just out of sight, above her head-not in the heavens as many have suggested. Four hundred years later, Wittgenstein - at the peak of his logical powers-talked like the Western incarnation of the Buddha in asserting that what he sought was already here and now. Dürer, having long since found his own incarnation of enlightenment, and logical high, would no doubt have smiled in agreement.

I have used a metaphor for chaos in the development of a model of mental health nursing practice at the University of Newcastle. The tidal model acknowledges the chaotic nature of human experience-predictable only in its unpredictabil- ity. ${ }^{19}$ The metaphor emphasises the power and unpredictability of the sea, echoing the power and unpredictability of mental illness. The ebb and flow of our lives, is an echo also of the delicate balance between illness and health. We breathe in and out like waves lapping at the shore. In Eastern thought the breath-the prana or life force-heralds life with each inhalation, and death with each exhalation. We are constantly on the tidal cusps of life and death. Life is a river of experience in which we all shall, ultimately, drown. Water is a powerful metaphor for life since as a species we emerged from the sea, and all of us from the waters of our mother's womb. Water is a universal metaphor for cleansing of the spirit and the idea of drowning is used frequently by people overwhelmed by their experiences. The power of water also is difficult to contain, and we learn how to live with its power by learning to swim or by building boats or dams.

The becalming of the ancient mariner evokes for many people the experience of depression, especially when it is guilt-ridden. For others, psychiatric crisis is like being dashed onto the rocks, and psychiatric rescue needs to be an efficient and dramatic form of life-saving. If we are to help people to understand better the weakness in their constitution (leaky boats spring to mind) or the threats that lie beneath the waterline of their lives, we need to do some repair work or deep sea diving-both metaphors for psychotherapy. At other times the health care focus is more limited in its objectives, aiming to keep people afloat - on their wider ocean of experience.

The significance of the tidal metaphor was summed up neatly by Shakespeare, when his Julius Caesar said:

"There is a tide in the affairs of men,

Which, taken at the flood, leads on to fortune;

Omitted, all the voyages of their life

Is bound in shallows and miseries."20

And Dickens acknowledged the tidal metaphor of life and death, when Mr Peggotty said:

"People can't die along the coast, except when the tide's pretty nigh out. They can't be born, unless its pretty nigh in-not properly born, till flood. He's a going out with the tide.”22

These plaintive lines show Dickens's knowledge of Shakespeare, and also his intuitive empathy with the eastern notion of the prana.

When I first offered this paper, at a conference at the Royal Society of Arts, I used a small selection of images from a remarkable collection of psychiatric art, as the unspoken backdrop to my verbal discourse. All the pictures were taken from the Eric Cunnigham Dax collection, from Melbourne. ${ }^{22} \mathrm{Dr}$ Dax has collected psychiatric art for over sixty years and I have been privileged to view and discuss his collection, several times. Regrettably, he believes that psychiatrists, and indeed nurses and other disciplines, are no longer greatly interested in the insights available from art-about patients or 
perhaps even themselves. Perhaps these visual metaphors take us too close to the edge of the fragile construction we call sanity.

I have regularly used these pictures in my teaching as a means of exploring our construction of the world of others - and ourselves. As they flashed up on the screen, as I presented my paper, I wondered what the audience thought they said about the person who made them? I wondered also what kind of emotions they stirred, metaphorically, in the audience? I wondered what echoes might be heard within the individual members of the audience, as well as collectively, if silently, within the hall?

I am sure it is possible to spend a productive life in health care without ever considering the variegated meanings of the illness experience-what Simon Champ might call its ontological significance. But if we are willing to go beyond the subject-object duality, that Pirsig talked about, we might foster a sense of caring with the person, where our healing sap might begin to rise, and that might add an interesting dimension to health care. In reading books and poems; in listening to the spiritual enactments of the dramatist; in learning the discipline of studying paintings, sculpture, and film we might shape a form of knowledge within us, that cannot be found "out there", but is not to be found "inside" ourselves, either.

Phil Barker is Professor of Psychiatric Nursing Practice, Department of Psychiatric Nursing Practice, School of Psychiatry, University of Newcastle upon Tyne, Newcastle upon Tyne.

\section{References and notes}

1 Given that the experience of life can only ever be personal, the personal pronoun appears appropriate.

2 Szasz TS. Insanity: the idea and its consequences. New York: Wiley, 1987

3 Lewis CS. The pilgrim's regress. New York Bantam, 1981.

4 Barker P. The philosophy and practice of psychiatric nursing. Edinburgh: Churchill Livingstone, 1999: 103.

5 See reference 2: 137 .

6 Heidegger M. Being and time. London: SCM Press, 1961.

7 Pirsig R. Zen and the art of motor cycle maintenance. London: Corgi, 1974.

8 Watts A. The way of Zen. Harmonsdworth: Penguin, 1962: 138.

9 Hanh TN. Zen keys: a guide to Zen practice. London: Thorsons, 1995: 40.

10 Brandon D. The Tao of survival. Birmingham, UK: Venture Press, 2000.

11 Yeats WB. Among school children. The tower. London: Macmillan, 1928.

12 Barker P, Campbell P, Davidson B. From the ashes of experience: reflections on madness, recovery and growth. London: Whurr, 1999.

13 See reference 12: 62

14 Gournay K. New facts on schizophrenia. Nursing Times 1995;91,25:32-3.

15 Cox M, ed. Hamlet and Romeo: Mark Rylance interviewed by Rob Ferris. In: Shakespeare comes to Broadmoor. London: Jessica Kingsley, 1992: 33.

16 Mitchell S. The enlightened mind. New York: Harper Collins, 1991: 186-7.

17 See reference 16: 191-2.

18 See reference 16: 199

19 Barker P. The tidal model: theory and practice. Newcastle-uponTyne: University of Newcastle, 2000.

20 Shakespeare W. Fulius Caesar. Harmondsworth: Penguing, 1967.

21 Dickens C. David Copperfield. Oxford: Clarendon Press, 1981.

22 Dax EC. The Eric Cunningham Dax collection: selected works of psychiatric art. Melbourne: Melbourne University Press, 1998.

\section{News and notes \\ Call for papers}

We intend that from issue three onwards, Medical Humanities will alternate between a general issue published each June and thematic issues published each December. The general issues will provide a forum for papers and discussions of various topics, arising either independently or in response to papers published in previous issues of the journal; these non-thematic issues will none the less continue to pursue our general aim of seeking to explore the "integrated conception" of the medical humanities-that conception according to which the perspectives of the humanities and social sciences are regarded as belonging at the core of medical knowledge and practice. Original, high quality papers on topics falling within this general aim are invited.

The thematic issues will be announced at least two issues (one calendar year) in advance of publication. The first of these, to be published in December 2001, will be devoted to "The role of the imagination in science and scientific medicine". Original, high quality papers are sought for this issue. Contributors should follow the guidance given at our website (www. medicalhumanitiescom) and should submit contributions to the editors at the address shown. Informal discussion with the editors prior to submission is welcomed.

f Med Ethics: Medical Humanities 


\section{Book reviews}

\section{Unhealthy Societies- the Afflictions of Inequality}

Richard Wilkinson, London, Routledge, 1996, xi +255 pages, $£ 17.99$ (sc).

Why read this book? Read it if you are interested-professionally or otherwisein the current state of society and the effects this has on our health. And in this case read it even if the complexities of epidemiological research, of anthropology, of social psychology, economics, history or politics are not your homeground: for though the book draws on all these areas it can and should be read from cover to cover.

Wilkinson's thesis concerns the relationship between relative income and mortality. He shows this relationship to hold very strongly within a given society or social grouping, ie it is the distribution of income rather than its absolute level which seems the more important, particularly so in developed countries. Wilkinson shows early on how relative deprivation becomes a major determinant of health once a society has passed through the socalled "epidemiological transition"where predominantly infectious causes of death give way to predominantly degenerative causes (cancer, cardiovascular disease, stroke etc), and where the stark relationship between lifeexpectancy and per capita income declines as absolute incomes rise. (Interestingly, this also seems to mark a change in the social distribution of some major diseases including most importantly coronary heart disease: in affluent societies the so-called "diseases of affluence" actually shift to the poor.)

Wilkinson then looks for possible explanations for those inequalities in health that are associated with living standards. Genetics, and anomalies of classification or measurement, are shown to contribute nothing; the effects of social mobility, medical care and individual health related behaviour provide only a partial influence. This leaves as the major influence the effects of the social and economic circumstances in which people live "Health ... gives us a handle of hard data on the subjective impact of experience ... [We] are discovering the toxicity of social circumstances and patterns of social organisation."

Wilkinson develops the case for regarding relative income as the more important factor, by re-examining existing data from a new conceptual standpoint, illustrated by neat historical case studies. He considers on the one hand societies experiencing a rapid compression of income distribution, accompanied by dramatic improvements in life-expectancy (as, twice, in wartime Britain); and on the other hand societies experiencing a rapid widening of income differentials, resulting in a breakdown of community cohesion and a sharp increase in deaths from coronary heart disease (as in the small close-knit Italian-American community of Roseto, Pennsylvania in the 1960s). The picture starts to emerge strongly: "inequalities are not an inescapable fact of modern life".

From here the author develops the concept of social cohesion. He draws on a wealth of anthropological literature, and on ideas from the field of social psychology, to establish the reality of this concept and, more significantly, its crucial role in human health. The huge themes this raises are worth some quotation: "[We] live in ways that are not conducive to social harmony because we are protected [by an overriding authority] from most of the social consequences of doing so ... only under [that authority's] jurisdiction can the complaints of the dispossessed be safely ignored. "[We] come to believe that human beings are by nature what their culture suggests they are ... [We] fail to realise how soon a different social order might come to seem a reflection of a different human nature."

The latter part of the book deals with the possible physical pathways involved. One of the most plausible is the role of chronic stress mediated through the hypothalamic-pituitaryadrenal axis linked to raised corticosteroids, central obesity, insulin resistance, poor lipid profile and increased blood-clotting-with evidence linking all this to the social ordering of the population.

The range and depth of this book do not lend it to compression, since it reads as a whole: it gathers weight and momentum and it strikes up major themes which seem to resonate and coalesce of their own volition, while maintaining an open and balanced feel. The merits of this book lie not only at the level of detailed content (which will inevitably date as research moves on). It can already be seen as a pivotal point in the direction of related research. Its methodology is attractive to the medical humanities, because it runs counter to the fashion for subdisciplines guarding ever-smaller areas of exclusive expertise, and because it deals with complex issues straddling several disciplines. The value of conceptual thinking is outstandingly demonstrated, as "evidence" takes on new meanings from different viewpoints. Moreover it refocuses attention on the subjective quality of life as crucial for assessments of social vitality, making material and economic aspects of secondary and indirect importance.

Finally the text is accessible, it assumes no specialist knowledge, and it manages to evoke genuine excitement at the "first views of the landscape ahead". Read on!

RICHARD EVANS

General Practitioner, Swansea, UK

\section{Clinical Judgement- Evidence in Practice}

R S Downie, Jane Macnaughton, Oxford, OUP, 2000, 212 pages, $£ 19.95$.

The authors define the aims of this book as being: (1) to make a case for the centrality and irreplaceability of clinical judgment; (2) to identify the elements of good clinical judgment, and (3) to suggest how these might be developed by using the humanities in medical education.

The book's message could be summarised as "evidence based practice is not enough". The case is made by looking at four elements of judgment. Science is not merely a question of facts but also of their interpretation and the construction of theories, matters of judgment. Clinical judgment is needed to apply the general principles of scientific medicine to the individual, who is never identical with the average patient. The two chapters which discuss these topics, although worthy, are 
in the traditional rather ponderous style of British philosophy, and might have least appeal for those who most need to read them.

The chapter on humane judgment is easier reading and more interesting, exploring the relationship between autonomy, consumerism and professional judgment. A brief chapter on judgment in public health is followed by perhaps the best chapter, a clear account of both the facts and values of rationing. This would be an excellent text to give on an introductory course on this important issue, and I have little doubt that I shall use it as such. The final chapter rehearses the arguments in favour of the medical humanities, which are likely to be well known to readers of this journal.

Paradoxically, perhaps because of my background in experimental psychology, I couldn't help feeling that many of the chapters could themselves have benefited from a bit more evidence-particularly those on clinical judgment and the benefits of teaching the humanities, where empirical research has as much to teach us as philosophy.

The book certainly makes the case for clinical judgment, although not always in a very accessible way. Whilst it includes some interesting insights into the nature of clinical judgment, and into the place of medical humanities in its development, I did not feel that the authors really achieved their second and third aims. As a whole I found it hard to see for whom the book was written. Those committed to the view that medicine is both a humanity and an art will find little new here, whilst those still locked in a positivist time-warp (and sadly there are still many such souls in purgatory) might find the style too discursive and philosophical to stick with it.

PETER TOON General practitioner, London, UK

\section{Just a Head: Stories in a Body}

Denise Fassett and M R Gallagher, Australia, Allen \& Unwin, 1998, 148 pages, $£ 12.99$

"I was no longer an academic, a runner, a skier or a traveller. Essentially I became just a head. My body was gone: I was no longer a physical being." This is how M R Gallagher, previously a diabetes researcher and triathlete from Tasmania, begins this account of her five-year experience of illness, cowritten with friend and nursing lecturer Denise Fassett. After an asthma attack and ten days in intensive care she found she was unable to move her arms and legs, had difficulty swallowing and continuing problems breathing. Tests did not reveal a cause and as she becomes more and more disabled, $M$ $\mathrm{R}$ finds herself in the "medical wilderness of the psychosomatic". There is no cure. Five years later she remains in a nursing home, wheelchair-bound, with poor vision and generalised pain. She is surrounded by and attached to the paraphernalia of disability: a catheter, a feeding tube, and a voiceactivated computer. The reader is ultimately left uncertain about whether there is a physical diagnosis. M R's experience of her illness has led her to campaign for her own and others' assisted suicide and she plans a $\mathrm{PhD}$ to explore the doctor-patient relationship.

At the heart of the book is M R's struggle for a physical diagnosis. Her faith in science, the hospital's apparent narrow-mindedness, her disembodiment through the experience of hospitalisation and lack of diagnosis become a potent barrier to recovery. When the doctors finally give up and she becomes a "psych consult", her condition deteriorates dramatically. She herself, her co-author, Fassett, and perhaps some of the hospital staff, equate this label with blame, stigma and a disease that is no longer "genuine". She is happy to receive psychotherapy and antidepressants for her depression but not to treat her physical symptoms.

Fassett is explicit in her aim as co-author to tell M R's story as an "ill person", using narrative as a "research technology", not to find out why she has become ill. In doing so she narrows the scope of the book but provides a rarely performed service of documenting the distressing situation in which patients with severe unexplained symptoms in a medicalised setting can find themselves. $M$ R's inability to obtain a label to legitimise her symptoms only seems to make her more ill and angry. Doctors, nurses and other professionals emerge murkily from the narrative. They are largely distant, unsympathetic figures who are portrayed emphasising $M$ R's objectification of her body.

At one point $\mathrm{M} \mathrm{R}$ reminds us of Smyth's adage: “ask not what disease the person has but what person has the disease". Paradoxically, this book, conceived as the story of a personal journey through illness, fails to answer this central question. Behind Fassett's insistent intellectualisation, I felt I learnt very little of M R's everyday life, her relationships, her family and her prior history. I was disappointed that the book didn't tackle some of the crucial issues. How can a person end up in such a disabled state if there is no apparent cause? Has the medical system colluded to make her ill? Would a label early in her disease have helped her to get better? Why does she think she will never get better? In M R's case, like many others, a complex mixture of organic disease, iatrogenesis, psychological, social and cultural factors are probably at work.

M R's story will be sadly familiar to anyone working in neurology, liaison psychiatry or rehabilitation medicine. She is one of the "undiagnosed": the most severe end of the spectrum of medically unexplained symptoms that make up one third of hospital outpatients and an even greater proportion of general practice work. Patients like M R are not rare-up to ten per cent of patients in young disabled units in the UK may fall into a similar category.

Health professionals often find patients like M R difficult to help. Discussing psychosocial factors that may be important in the genesis or maintenance of illness, and the performing of tests that are negative, can alienate patients, yet a failure to do so would be negligent. This dilemma, found every day in most medical practice, reflects the poor schemata and linguistics that we have for dealing with human somatic distress.

JON STONE

Research fellow in Neurology, Edinburgh, UK

\section{Correction}

In the December 2000 issue of Medical Humanities the following acknowledgements were inadvertently omitted: Barker P, Metaphors of life and death and Richardson R, A necessary inhumanity.

The original versions of the papers on which these articles are based were first presented at a conference, The Healing Arts: the Role of the Humanities in Medical Education, held at the Royal Society of Arts on 30th March 2000. The papers are reproduced in their original form, complete with illustrations, in D Kirklin and R Richardson, eds. Medical Humanities: an Introduction. London: Royal College of Physicians, 2001. 